\title{
Cannabis use and risk of lung cancer: a case-control study
}

\author{
S. Aldington*, M. Harwood*, B. Cox* ${ }^{\#}$ M. Weatherall ${ }^{\star}$, L. Beckert*, A. Hansell ${ }^{+}$, \\ A. Pritchard*, G. Robinson* and R. Beasley* ${ }^{\star \S}$ on behalf of the Cannabis and \\ Respiratory Disease Research Group
}

ABSTRACT: The aim of the present study was to determine the risk of lung cancer associated with cannabis smoking.

A case-control study of lung cancer in adults $\leqslant 55$ yrs of age was conducted in eight district health boards in New Zealand. Cases were identified from the New Zealand Cancer Registry and hospital databases. Controls were randomly selected from the electoral roll, with frequency matching to cases in 5-yr age groups and district health boards. Interviewer-administered questionnaires were used to assess possible risk factors, including cannabis use. The relative risk of lung cancer associated with cannabis smoking was estimated by logistic regression.

In total, 79 cases of lung cancer and 324 controls were included in the study. The risk of lung cancer increased $8 \%$ (95\% confidence interval (CI) 2-15) for each joint-yr of cannabis smoking, after adjustment for confounding variables including cigarette smoking, and $7 \%(95 \% \mathrm{Cl} 5-9)$ for each pack-yr of cigarette smoking, after adjustment for confounding variables including cannabis smoking. The highest tertile of cannabis use was associated with an increased risk of lung cancer (relative risk 5.7 (95\% $\mathrm{Cl} 1.5-21.6)$ ), after adjustment for confounding variables including cigarette smoking.

In conclusion, the results of the present study indicate that long-term cannabis use increases the risk of lung cancer in young adults.

KEYWORDS: Cannabis, case-control, lung cancer, tobacco

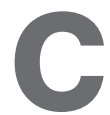

annabis smoking may have a greater potential than tobacco smoking to cause lung cancer [1-4]. Cannabis smoke is qualitatively similar to tobacco smoke, although it contains up to twice the concentration of the carcinogenic polyaromatic hydrocarbons [1]. Cannabis cigarettes are less densely packed than tobacco cigarettes, and tend to be smoked without filters [2] to a smaller butt size [3], leading to higher concentrations of smoke inhaled. Furthermore, smokers of cannabis inhale more deeply and hold their breath for longer [4], facilitating the deposition of the carcinogenic products in the lower respiratory tract. These factors are likely to be responsible for the five-fold greater absorption of carbon monoxide from a cannabis joint, compared with a tobacco cigarette of similar size despite similar carbon monoxide concentrations in the smoke inhaled [4]. Several studies have demonstrated pre-cancerous histological $[5,6]$ and molecular [7] abnormalities in the respiratory tracts of cannabis smokers, and the carcinogenic

For editorial comments see page 227. effects of cannabis smoke have been demonstrated in vitro [8] and in different in vivo animal models $[1,9,10]$. Conversely, there is also evidence that delta-9-tetrahydrocannabinol may have anti-carcinogenic effects [11-13].

Epidemiological evidence for an association between cannabis and lung cancer is limited and conflicting. Case series have suggested a causative role for cannabis in lung cancer in young adults [14, 15]. The case-control studies published to date have shown both the presence [16-18] and absence [19] of an association, but have been limited by the inability to quantify use [16-18], confounding with combined cannabis and tobacco use [16-18], and studies being undertaken in populations in which use may have serious legal consequences resulting in potential information bias [16-19] and poor response rates [19].

New Zealand represents an ideal country in which to study the association between cannabis and respiratory tract cancer. New Zealand has a high rate of cannabis use [20], and cannabis is

\section{AFFILIATIONS}

* Medical Research Institute of New Zealand,

Wellington School of Medicine \& Health Sciences, Wellington,

\#Hugh Adam Cancer Epidemiology Unit, University of Otago, Dunedin, New Zealand

+'Imperial College London, London, and

§University of Southampton,

Southampton, UK.

CORRESPONDENCE

R. Beasley

Medical Research Institute of New Zealand

PO Box 10055

Wellington

New Zealand

Fax: 6444729224

E-mail: Richard.Beasley@

mrinz.ac.nz

Received:

May 312007

Accepted after revision:

August 212007

SUPPORT STATEMENT

Funding was provided by The New Zealand Ministry of Health, The Hawke's Bay Medical Research

Foundation. B. Cox was funded by the Director's Cancer Research Trust. A. Hansell is a Wellcome Trust Intermediate Clinical Fellow supported by grant number 075883 . The funding bodies had no role in the design, data analysis or drafting of the manuscript.

\section{STATEMENT OF INTEREST}

A statement of interest for this study can be found at

www.erj.ersjournals.com/misc/ statements.shtml

European Respiratory Journal

Print ISSN 0903-1936

Online ISSN 1399-3003 
rarely mixed with tobacco within the joint [21], as is the custom in the UK [22]. New Zealand has among the highest rates of lung cancer worldwide with the indigenous Maori population having the highest incidence of any ethnic group [23]. These circumstances provided the opportunity to undertake a casecontrol study to investigate the association between lung cancer and cannabis use in young people.

\section{METHODS}

\section{Study participants}

Cases were patients with confirmed lung cancer aged $\leqslant 55$ yrs at the time of diagnosis, identified from hospital databases and the New Zealand Cancer Registry between January 2001 and July 2005. Hospital databases were also used because a few clinical-only diagnoses of lung cancer are not received by the Cancer Registry [24]. Cases were a mixture of prevalent and incident cases of lung cancer. Subjects were excluded if they had lung metastasis from a distant primary site other than lung, or a histological diagnosis of carcinoid or melanoma. Age at diagnosis, anatomical location of their malignancy and histological type were collected for cases. Controls without lung cancer were randomly selected from the electoral roll and frequency matched in 5-yr age groups and district health boards. Subjects came from eight district health board regions, serving both urban and rural populations. The eight district health boards serve together $\sim 1.8$ million people, representing just under one-half of the total New Zealand population. The present study was approved by the regional ethics committees and each participant gave written informed consent. Patients with cancer of the head and neck were also interviewed, but will be reported separately.

\section{Methods}

Questionnaires were administered face-to-face by trained interviewers, usually at the home of the participant. Information on demographics (including ethnic group), smoking history, passive smoking exposure, recreational drug use, diet, occupation, income, education, alcohol consumption and family history of malignancy was collected. A family history of lung cancer was defined as having a sibling or parent with lung cancer. Occupations associated with a higher risk of lung cancer were identified from the literature and subjects were assigned a "duration at risk" value in years. Ethnicity was derived by priority coding of the responses into the following three groups: Maori, Pacific Islander and "other". The highest level of educational attainment was recorded, as was income at diagnosis (or reference age). Alcohol consumption was calculated using a semi-quantitative score based on amount and frequency of consumption.

Subjects who reported having ever smoked $\geqslant 20$ joints of cannabis were then asked to complete a more detailed exposure questionnaire regarding their cannabis smoking. This questionnaire obtained information about the age of starting cannabis use, the amount, frequency and duration of use, and the characteristics of their smoking. This information was collected for each period of their lives when pattern of use changed and was then summed to give an estimate of total lifetime use. If subjects smoked cannabis in a form other than a joint, e.g. pipes or bongs, they were asked to estimate the number of cannabis joints to which that would equate. This conversion allowed cannabis use for all participants to be quantified in joint-yrs of use, with 1 joint-yr being equivalent to 1 joint per day for 1 yr. Subjects who had smoked $<20$ and $\geqslant 20$ cannabis joints in their lifetime were classified as nonsmokers and smokers of cannabis, respectively. A similar approach of determining lifetime use of cigarettes was employed to enable pack-yrs of cigarette smoking to be calculated, with 1 pack-yr being equivalent to 20 cigarettes per day for $1 \mathrm{yr}$. Subjects who reported smoking tobacco cigarettes occasionally but never daily, or daily at some stage in their life, were classified as nonsmokers and smokers of cigarettes, respectively. The questionnaire was piloted among ex-cannabis smokers.

\section{Analysis}

Standard methods for analysis of case-control studies were used. The mean delay from diagnosis to interview was subtracted from the date of interview to calculate a reference date for duration of exposure for each control. Tertiles of cannabis use were determined by the marginal distribution of use for all subjects to reduce the chance of zero cell counts if just the control group was used. Relative risks (RRs) were estimated by calculating odds ratios by logistic regression and adjusted for confounding variables. Adjustment for age, jointyrs of cannabis smoking and pack-yrs of cigarette smoking was made by including them as continuous variables in the regression models. The effects of categories of pack-yrs of cigarette smoking (quintiles of smoking for all subjects interviewed) and joint-yrs of cannabis smoking (tertiles of use for all subjects interviewed) were also assessed.

The RRs were also calculated based on cannabis use up to 5 yrs prior to diagnosis or a reference date in the controls, as exposure after that time was unlikely to have caused the malignancy. This 5-yr period was based on natural growth rates for lung cancer, in which the mean time from malignant change to diagnosis is at least 8 yrs for nonsmall cell lung cancers, and $\sim 3$ yrs for small cell lung cancers $[25,26]$. The age at which cannabis smoking started was categorised, and the RR associated with starting at $<16$ yrs of age compared with $\geqslant 21$ yrs was estimated. Various logistic regression models were fitted with potential confounders as continuous and categorical variables, and the estimates of RR and the confidence intervals (CIs) were not appreciably different from the results presented. Differences in Akaike's Information Criteria (AIC) were used to assess the linearity of the doseresponse relationship of the risk of lung cancer after fitting parameters as continuous and categorical variables.

\section{Power calculation}

Assuming that $15 \%$ of the population smokes cannabis, a sample size of 75 cases and 300 controls had 80 and $90 \%$ power at a type 1 error rate of $5 \%$ to detect an odds ratio of lung cancer of 2.4 and 2.7 , respectively.

\section{RESULTS}

A total of 102 eligible cases were contacted and invited for interview, of whom 79 (77\%) agreed to participate. A total of 493 controls were contacted and invited for interview, and 324 $(66 \%)$ agreed to participate. The frequency distribution of cases and controls interviewed for selected characteristics is shown in table 1. 


\section{TABLE 1 The frequency distribution of cases and controls for selected variables}

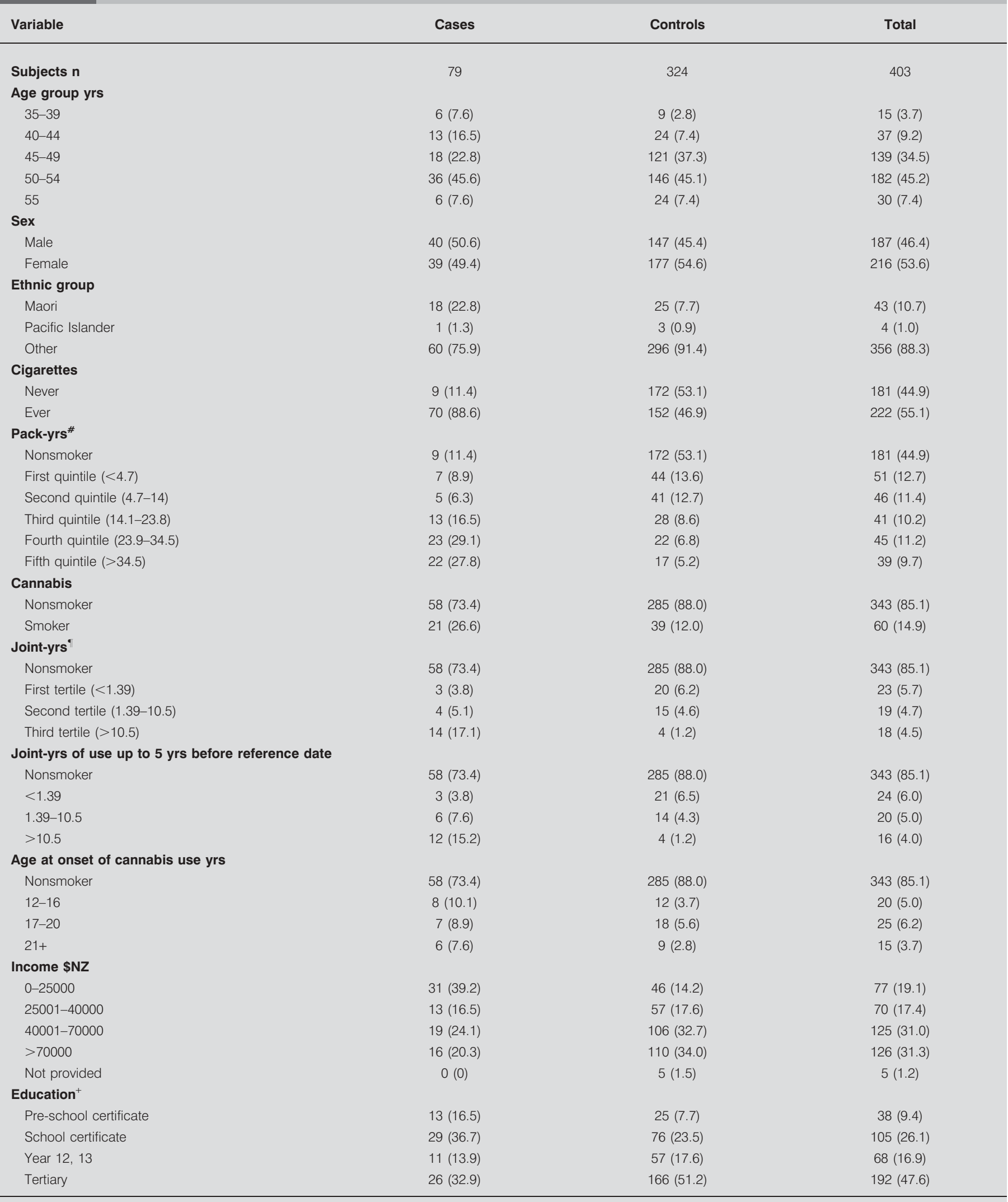

Data are presented as $\mathrm{n}(\%)$ unless otherwise indicated. ${ }^{\#}$ : one pack of 20 tobacco cigarettes smoked per day for 1 yr; ": one cannabis joint smoked per day for 1 yr; ${ }^{+}$: School certificate: New Zealand Secondary School Certificate Examination (age 15, 16), year 12, 13 (age 17, 18) were previously forms 6 and 7. 
TABLE 2 Tobacco use, cannabis use and alcohol consumption and risk of lung cancer

\begin{tabular}{|c|c|c|c|c|}
\hline \multicolumn{5}{|c|}{ Cigarette smoking ${ }^{\#}$} \\
\hline Ever & 70 & 152 & 6.7 & $3.1-14.0$ \\
\hline \multicolumn{5}{|l|}{ Pack-yrs ${ }^{\#}$} \\
\hline Nonsmoker & 9 & 172 & 1.0 & \\
\hline Third quintile & 13 & 28 & 6.1 & $2.2-16.4$ \\
\hline Fourth quintile & 23 & 22 & 12.3 & $4.7-32.7$ \\
\hline Fifth quintile & 22 & 17 & 23.9 & $8.7-65.5$ \\
\hline \multicolumn{5}{|l|}{ Cannabis use } \\
\hline Nonsmoker & 58 & 285 & 1.0 & \\
\hline Second tertile & 4 & 15 & 0.5 & $0.1-2.0$ \\
\hline Third tertile & 14 & 4 & 5.7 & $1.5-21.6$ \\
\hline \multicolumn{5}{|c|}{$\begin{array}{l}\text { Joint-yrs up to } 5 \text { yrs prior to reference } \\
\text { date }\end{array}$} \\
\hline Nonsmoker & 58 & 285 & 1.0 & \\
\hline First tertile & 3 & 21 & 0.3 & $0.1-1.3$ \\
\hline Second tertile & 6 & 14 & 0.9 & $0.3-2.9$ \\
\hline Third tertile & 12 & 4 & 5.2 & $1.3-20.4$ \\
\hline \multicolumn{5}{|c|}{ Alcohol consumption $^{+}$} \\
\hline None & 5 & 22 & 1.0 & \\
\hline Light & 30 & 126 & 0.6 & $0.2-2.1$ \\
\hline
\end{tabular}

RR: relative risk; Cl: confidence interval. ${ }^{*}$ : adjusted for age, sex, ethnicity, family history of lung cancer, and joint-yrs of cannabis use. ": adjusted for age, sex, ethnicity, family history of lung cancer and pack-yrs of cigarette smoking. ${ }^{+}$: adjusted for age, sex, ethnicity, family history of lung cancer, pack-yrs of cigarette smoking and joint-yrs of cannabis use. Alcohol consumption was measured using a semiquantitative scale. Cigarette use (pack-yrs) quintiles were: <4.7, 4.7-14, 14.1-23.8, 23.81-34.5 and $>34.5$. Cannabis use (joint-yrs) tertiles were: $<1.39,1.39-10.5$ and $>10.5$

The 79 cases of lung cancer included $16(20 \%)$ small cell and 63 $(80 \%)$ nonsmall cell cancers. This is consistent with the established distribution of histological type seen in the general population [27]. There were 39 (49\%) female cases of lung cancer, similar to the female proportion $(60 \%)$ of all lung cancer cases aged $<55$ yrs in New Zealand in 2002 [28]. In 2002 in New Zealand, $21 \%$ of cancer registrations among people $<55$ yrs of age occurred in Maori subjects compared with 23\% of the cases interviewed. Also, there were 19 (24\%) cases interviewed aged $<45$ yrs, similar to the proportion $(23 \%)$ aged $<45$ yrs amongst all lung cancer cases aged $<55$ yrs [28]. The controls $(n=324)$ who participated were similar to those who did not $(n=169)$ in terms of age $(11$ versus $13 \%<45 \mathrm{yrs})$ and sex (55 versus 51\% female). However, eligible Maori control subjects were less likely to respond, with $9 \%$ of controls who participated being Maori compared with 15\% of controls who did not participate.

The RR of lung cancer did not vary with age, due to cases and controls being frequency matched on 5-yr age group to improve the efficiency of the study. A family history of lung cancer was associated with an increased risk of lung cancer $(\mathrm{RR}=3.9,95 \% \mathrm{CI} 1.8-8.4)$. There was no significant association between lung cancer risk and passive smoking, diet, occupation, income, educational level and alcohol use after adjustment for age, sex, ethnicity, cigarette smoking and a family history of lung cancer. The proportion of controls (aged 3555 yrs) who had ever smoked cannabis, with age-adjustment for the age distribution of the general population was $36 \%$, similar to the $40-52 \%$ reported amongst the younger $15-45 \mathrm{yr}$ age group in New Zealand population surveys undertaken between 1990 and 2001 [20].

While cannabis smoking (defined as lifetime use of $\geqslant 20$ joints) was not associated with a significantly increased risk of lung cancer (table 2), those with the highest tertile of use $(>10.5$ joint-yrs of exposure) had a significantly increased risk (RR 5.7 (95\% CI 1.5-21.6)) after adjustment for age, sex, ethnicity, pack-yrs of cigarette smoking and a family history of lung cancer. When the analysis was restricted to non-Maori subjects, the RR was 5.9 (95\% CI 1.2-28.5). Using the prevalence of the highest tertile of cannabis smoking of the controls, it was 


\begin{tabular}{|c|c|c|c|}
\hline TABLE 3 & \multicolumn{3}{|c|}{$\begin{array}{l}\text { Cannabis use and tobacco use, as continuous } \\
\text { variables, and risk of lung cancer }\end{array}$} \\
\hline Characterist & & RR of lung cancer & $95 \% \mathrm{Cl}$ \\
\hline \multicolumn{2}{|c|}{ Pack-yr of cigarette smoking\# } & 1.07 & $1.05-1.09$ \\
\hline \multicolumn{2}{|c|}{ Joint-yr of cannabis smoking } & 1.08 & $1.02-1.15$ \\
\hline \multicolumn{2}{|c|}{$\begin{array}{l}\text { Joint-yrs to } 5 \text { yrs prior to diag- } \\
\text { nosis }^{+}\end{array}$} & 1.10 & $1.02-1.18$ \\
\hline
\end{tabular}

RR: relative risk; Cl: confidence interval. \#: adjusted for age, sex, ethnicity, family history of lung cancer and joint-yrs of cannabis use. ": adjusted for age, sex, ethnicity, family history of lung cancer and pack-yrs. ${ }^{+}$: adjusted for age, sex, ethnicity, family history of lung cancer, pack-yrs and age of onset of cannabis use.

estimated that $\sim 5 \%$ of lung cancer in those aged $\leqslant 55$ yrs in New Zealand may be attributable to cannabis smoking.

When joint-yrs of use were fitted as a continuous variable, thus providing greater statistical power than the assessment by tertile of use, a significant increasing risk of $8 \%$ with each joint$\mathrm{yr}$ of use was found $(\mathrm{RR}=1.08,95 \%$ CI 1.02-1.15; table 3 ). This estimate was unaltered when the analysis was restricted to non-Maori subjects. The difference in AIC between the model fitting joint-yrs of use as a continuous variable and that fitting tertiles of use was 2.23, indicating no clear discernment between a threshold and continuous effect of cannabis use and risk of lung cancer.

The strength of the association was maintained when cannabis use in the 5 yrs prior to diagnosis, or reference date for controls, was excluded ( $R R=1.10,95 \%$ CI 1.02-1.18; table 3$)$. A significant increase in the risk was also observed with increasing cigarette smoking, with a $7 \%$ increase in risk for each pack-yr of exposure $(\mathrm{RR}=1.07,95 \% \mathrm{CI} 1.05-1.09)$, after adjustment for confounding variables including cannabis smoking. Therefore, the increased risk for each pack-yr of cigarette smoking was similar to that for each joint-yr of cannabis use.

Among users of cannabis no significant correlation between joint-yrs of use and age of onset of use was found (Pearson correlation coefficient $0.077, \mathrm{p}=0.56$ ). Compared with subjects who started smoking cannabis aged $\geqslant 21$ yrs, those that started under the age of 16 had a RR of lung cancer of 10.3 (95\% CI $0.8-$ 132) after adjustment for joint-yrs of cannabis use, pack-yrs of cigarette smoking, age, sex, ethnicity and a family history of lung cancer. After adjustment for joint-yrs of use, age, sex, ethnicity, a family history of lung cancer and pack-yrs of cigarette smoking, no significant decreasing trend in RR with years since last use was observed.

\section{DISCUSSION}

This population-based, case-control study provides evidence of a relationship between smoking cannabis and lung cancer in young adults. For each joint-yr of cannabis exposure the risk of lung cancer was estimated to increase by $8 \%$.

There are a number of methodological considerations relevant to the interpretation of these findings. The present authors studied subjects aged $\leqslant 55$ yrs due to published case series [14, 15], which suggested a strong association between cannabis use and lung cancer in young adults. Additionally, the lifetime exposure of older individuals would be expected to be much lower as they would have been older than the typical age for onset of use when the "epidemic" of cannabis use began in the 1960s. Due to the low incidence of lung cancer in this age group, representing $<10 \%$ of all lung cancers [23], cases diagnosed up to 5 yrs before interview were included. No information from deceased cases was sought. If survival after diagnosis was different for users compared with nonusers of cannabis, this may have influenced the results obtained. Cases were identified from both the National Cancer Registry and from hospital outpatient and discharge databases to ensure case ascertainment was as complete as possible.

In the initial approach, no mention was made of the primary risk factor of interest to avoid recruitment bias with either the cases or the controls. To minimise response bias, the interviewer did not state the specific research hypothesis and took a detailed history of all well-known risk factors. Cannabis exposure was measured as joint-yrs of cannabis use, which combines both the intensity (amount and frequency) and duration of use. This approach follows the current convention for quantifying life-long cannabis consumption and recognises the evidence that the risk of lung cancer with cigarette smoking is related to both intensity and duration of use [29]. Recall of the amount of cannabis smoked over a long period of time may have been difficult for some subjects; however, this is likely to have been similar for both cases and controls as subjects were not aware of the study hypothesis.

A population-based control group was used rather than a hospital-based control group as the latter is susceptible to significant bias due to the many medical conditions associated with cannabis use $[30,31]$. In recognition of the low incidence of lung cancer in the age group studied, four controls were studied for each case to increase the power of the study. Whilst eligible Maori control subjects were less likely to be interviewed, when confined to non-Maori subjects, the results were very similar to when they were included, suggesting that any differential control response by ethnicity was not a major confounder of the increased RR observed for lung cancer from cannabis use.

The major finding from the present study was that for each jointyr of cannabis exposure, the risk of lung cancer increased by $8 \%$, after adjustment for confounding variables including tobacco smoking. A major differential risk between cannabis and cigarette smoking was observed, with one joint of cannabis being similar to $\sim 20$ cigarettes for risk of lung cancer. This is consistent with the observation that smoking "a few" cannabis joints a day causes similar histological changes in the tracheobronchial epithelium as smoking 20-30 tobacco cigarettes a day [32]. It has also been reported that smoking two joints per day results in cytomorphological abnormalities in the sputum, similar to $\sim 30$ cigarettes per day $[33,34]$. These differential risks are greater than the 1:5 dose ratio between cannabis and tobacco for carbon monoxide levels and the 1:3 dose ratio for amount of tar inhaled [4]. This suggests that, as well as differences in smoking topography, in which cannabis joints are usually smoked without a filter [2], to a smaller butt size [3], using deeper and longer inhalation techniques [4], differences in chemical composition of cannabis and cigarette smoke may also 
be responsible for the differences in their lung cancer risks. In this regard, cannabis smoke has been shown to have greater concentrations of the carcinogenic polyaromatic hydrocarbons benz[a]pyrene and benz[a]anthracene than cigarette smoke [1].

The risk of lung cancer from cannabis use was restricted to the upper tertile of joint-yrs of use, with a 5.7-fold greater risk in those with $>10.5$ joint-yrs of cannabis use. However, it is unlikely that this represents a threshold effect, as a linear relationship has been clearly demonstrated between tobacco cigarette consumption and risk of lung cancer [35]. The lack of an association in the lower tertiles may be due to the relatively small number of cannabis users in the study and the young age of subjects reducing the time available for high numbers of joint-yrs to accumulate, resulting in low levels of exposure (up to 1.39 joint-yrs for the lower tertile).

Further analysis was undertaken in which the risk of lung cancer was assessed for cannabis use up to 5 yrs prior to the diagnosis. This approach was based on evidence that in most cases of lung cancer, the duration between malignant change and diagnosis is $>5$ yrs [26]. When cannabis use in the 5 yrs prior to diagnosis for the cases (and prior to the reference date for the controls) was excluded from the analysis the strength of the association was maintained, as would be expected if a causal association existed, with a $10 \%$ increase in risk for each joint-yr of exposure.

There was some suggestion that the risk of lung cancer may increase with earlier onset of cannabis use but the small number of subjects prevented more detailed assessment of this potential risk factor. However, such an association would be consistent with the evidence that the age of onset of tobacco smoking is a determinant of lung cancer risk [36, 37]. Further case-control studies are needed to quantify the lung cancer risk associated with cannabis use, including the influence of the age of starting cannabis smoking, the dose-response relationship, and the dose equivalence with cigarette smoking.

In the young adults presently studied, the population attributable risk for cancer of the lung with cannabis smoking was estimated to be $5 \%$. If any increased risk was maintained as these young people age, then a considerable burden from lung cancer due to cannabis smoking may occur in the future.

The present findings are consistent with the three North African case-control studies [16-18] that have reported a six- to eight-fold increased risk of lung cancer with cannabis smoking, although the lack of detailed smoking histories and the custom of mixing cannabis with tobacco may have contributed to the risks observed. In contrast, a large case-control study from California, USA, with an estimated participation rate in cases of only $39 \%$ reported no association between cannabis use and lung cancer [19]. The controls in the Californian study were matched for neighbourhood, which may have made detection of an association less likely, as cannabis use is likely to be similar within distinct neighbourhoods. This may have contributed to the higher rates of cannabis use in the controls than previously reported from California [38]. Also, AfricanAmerican people were less likely to have participated than other ethnic groups, suggesting significant selection bias may have occurred. A positive relationship between cannabis use and cigarette smoking was observed in the controls, but the opposite relationship was present in the lung cancer cases, which also suggests selection bias or differential reporting between cases and controls. The practice of mixing tobacco with cannabis in the joint appears to vary between populations and may contribute to the geographical variation in risk of lung cancer from cannabis use observed.

These studies, and the present study, highlight the difficulties inherent in undertaking epidemiological research of the effects of cannabis. While it is important to interpret the findings in the context of these limitations, the balance of evidence would suggest a positive association between cannabis and lung cancer. This issue is of major public health importance, due to the prevalent use of cannabis globally and lung cancer being responsible for over a million deaths in the world each year $[39,40]$. With the prevalence and mortality from lung cancer increasing, prevention by risk factor modification is of paramount importance. Major efforts are being made to reduce the prevalence of tobacco smoking [41]. The findings of the present study suggest that these public health programmes may need to include greater initiatives to reduce cannabis smoking and should be directed particularly at young people.

\section{APPENDIX}

\section{The Cannabis and Respiratory Disease Research Group}

Executive Steering Committee: S. Aldington, M. Harwood, A. Pritchard, G. Robinson and R. Beasley (Medical Research Institute of New Zealand, Wellington, New Zealand); B. Cox (University of Otago, Dunedin, New Zealand); M. Weatherall (University of Otago Wellington, Wellington, New Zealand); L. Beckert (Christchurch Hospital, Christchurch, New Zealand); and A. Hansell (Imperial College of Science, Technology and Medicine, London, UK).

Regional Coordinators: M. Tweed, B. Mahon (Wellington Hospital, Wellington, New Zealand); L. Beckert, M. Campbell (Christchurch Hospital, Christchurch, New Zealand); MJ. Sneyd (University of Otago, Dunedin, New Zealand); R. Armstrong, C. Crawford (Hawkes Bay Hospital, Hastings, New Zealand); A. Watson, A. Lobhan (Palmerston North Hospital, Palmerston North, New Zealand); N. Graham (Tauranga Hospital, Tauranga, New Zealand); S. Holt (Research Review, Tauranga, New Zealand); J. McLachlan, P. Swann (Waikato Hospital, Hamilton, New Zealand); S. Tan (Hutt Hospital, Lower Hutt, New Zealand); G. Lear, N. Sheikh (Gisborne Hospital, Gisborne, New Zealand).

\section{REFERENCES}

1 Hoffmann D, Brunnerman D, Gori G, Wynder E. On the carcinogenicity of marijuana smoke. Recent Adv Phytochem 1975; 9: 63-81.

2 Rickert W, Robinson J, Rogers B. A comparison of tar, carbon monoxide and $\mathrm{pH}$ levels in smoke from marijuana and tobacco cigarettes. Can J Pub Health 1982; 73: 386-391.

3 Tashkin D, Gliederer F, Rose J, et al. Tar, CO and THC delivery from the 1st and 2nd halves of a marijuana cigarette. Pharmacol Biochem Behav 1991; 40: 657-661.

4 Wu T, Tashkin D, Djahed B, Rose J. Pulmonary hazards of smoking marijuana as compared with tobacco. $N$ Engl J Med 1988; 318: 347-351.

5 Fligiel S, Roth M, Kleerup E, Barsky S, Simmons M, Tashkin D. Tracheobronchial histopathology in habitual 
smokers of cocaine, marijuana, and/or tobacco. Chest 1997; 112: 319-326.

6 Gong H, Fligiel S, Tashkin D, Barbers R. Tracheobronchial changes in habitual, heavy smokers of marijuana with and without tobacco. Am Rev Respir Dis 1987; 136: 142-149.

7 Barsky S, Roth M, Kleerup E, Simmons M, Tashkin D. Histopathologic and molecular alterations in bronchial epithelium in habitual smokers of marijuana, cocaine or tobacco. J Natl Cancer Instit 1998; 90: 1198-1204.

8 Busch F, Seid D, Wei E. Mutagenic activity of marihuana smoke condensates. Cancer Letters 1979; 6: 319-324.

9 Roy P, Magnan-Lapoint F, Huy N, Boutet M. Chronic inhalation of marijuana and tobacco in dogs. Recent Commun Chem Pathol Pharmacol 1976; 14: 305-317.

10 Zhu L, Sharma S, Stolina M, et al. Delta-9-tetrahydrocannabinol inhibits antitumour immunity by a CB2 receptormediated, cytokine dependent pathway. J Immunol 2000; 165: 373-380.

11 Bifulco M, Laezza C, Pisanti S, Gazzerro P. Cannabinoids and cancer: pros and cons of an antitumour strategy. $\mathrm{Br} \mathrm{J}$ Pharmacol 2006; 148: 123-135.

12 Guzman M. Cannabinoids: potential anticancer agents. Nat Rev Cancer 2003; 3: 745-755.

13 Hall W, MacDonald C, Currow D. Cannabinoids and cancer: causation, remediation and palliation. Lancet Oncol 2005; 6: 35-42.

14 Sridhar K, Raub W, Weatherby N, et al. Possible role of marijuana smoking as a carcinogen in the development of lung cancer at a young age. J Psychoactive Drugs 1994; 26: 285-288.

15 Fung M, Gallagher C, Machtay M. Lung and aero-digestive cancer in young marijuana smokers. Tumori 1999; 85: 140-142.

16 Sasco A, Merrill R, Dari I, et al. A case control study of lung cancer in Casablanca, Morocco. Cancer Causes Control 2002; 13: 609-616.

17 Hsairi M, Achour N, Zouari B, et al. Facteurs etiologiques du cancer bronchique primitif en Tunisie [Etiologic factors in primary bronchial carcinoma in Tunisia]. La Tunisie Medicale 1993; 71: 265-268.

18 Voirin N, Berthiller J, Benhaïm-Luzon V, et al. Risk of lung cancer and past use of cannabis in Tunisia. J Thorac Oncol 2006; 1: 577-579.

19 Hashibe M, Morgenstern H, Cui Y, et al. Marijuana use and the risk of lung and upper aerodigestive tract cancers: results of a population-based case-control study. Cancer Epidemiol Biomarkers Prev 2006; 15: 1829-1834.

20 Inquiry into the public health strategies related to cannabis use and the most appropriate legal status. Report of the Health Committee. Forty-seventh Parliament (Steve Chadwick, Chairperson), August 2003, presented to the House of Representatives. www.parliament.nz/NR/rdonlyres/571B77EC-27CF-41AA-8364-7800E36A214D/13988/ DBSCH_SCR_2531_23991.pdf. Date last accessed: November 14, 2007.

21 Wilkins C, Girling M, Sweetsur P, Butler R. : Cannabis and other illicit drug trends in New Zealand, 2005.:: Auckland, Massey University, 2005.

22 Britton J. Summary of long-term adverse effects of smoking marijuana on lung health. Report from the
Royal College of Physicians of London to the Select Committee Inquiry into Drugs, September 2001. London, Royal College of Physicians, 2001.

23 Parkin D, Whelan S, Ferlay J, Raymond L, Young J. Cancer Incidence in Five Continents. Vol. VII. Lyon, International Agency for Research on Cancer, Scientific Publication, 1997.

24 Stevens W, Stevens G, Kolbe J, Cox B. Lung cancer in New Zealand: patterns of secondary care and implications for survival. J Thorac Oncol 2007; 2: 481-493.

25 Spiro SG. Clinical features and assessment of lung cancer. In: Gibson GJ, Geddes DM, Costabel U, Sterk PJ, Corrin B, eds. Respiratory Medicine. 3rd Edn. London, Elsevier Science Ltd, 2003; pp. 1828-1849.

26 Geddes DM. The natural history of lung cancer: a review based on rates of tumour growth. Br J Dis Chest 1979; 73: 1-17.

27 Spiro S, ed. Lung Cancer. Eur Respir Mon 2001; 17.

28 New Zealand Health Information Service. Cancer Registrations and Deaths 2002. www.nzhis.govt.nz/stats/ index.html Date last updated: September 11, 2007. Date last accessed: October, 9: 2007.

29 Peto R. Influence of dose and duration of smoking on lung cancer rates. IARC Sci Publ 1986; 74: 23-33.

30 Khalsa JH, Genser S, Francis H, Martin B. Clinical consequences of marijuana. J Clin Pharmacol 2002; 42: Suppl. 11, 7S-10S.

31 Hall W, Solowij N. Adverse effects of cannabis. Lancet 1998; 352: 1611-1616.

32 Roth M, Arora A, Barsky S, Kleerup E, Simmons M, Tashkin D. Airway inflammation in young marijuana and tobacco smokers. Am J Respir Crit Care Med 1998; 157: 928-937.

33 Roby T, Hubbard G, Swan G. Cytomorphologic features of sputum samples from marijuana smokers. Diagnostic Cytopathol 1991; 7: 229-234.

34 Starr K, Renneker M. A cytologic evaluation of sputum in marijuana smokers. J Fam Pract 1994; 39: 359-363.

35 Doll R, Hill AB. Mortality in relation to smoking: ten years' observations of British doctors. BMJ 1964; 1: 1399-1410.

36 Wiencke JK, Thurston SW, Kelsey KT, et al. Early age at smoking initiation and tobacco carcinogen DNA damage in the lung. J Natl Cancer Instit 199, 91: 614-619.

37 Hirao T, Nelson NH, Ashok TDS, et al. Tobacco smokeinduced DNA damage and an early age of smoking initiation induce chromosome loss at 3p21 in lung cancer. Cancer Res 2001; 61: 612-615.

382005 National Survey on Drug Use \& Health: National Results. Appendix G: Selected Prevalence Tables. www. oas.samhsa.gov/NSDUH/2k5NSDUH/AppG.htm\#TabG-2 Date last updated: September 5, 2006. Date last accessed: October 9, 2007.

39 Parkin DM, Bray F, Ferlay J, Pisani P. Global cancer statistics, 2002. CA Cancer J Clin 2005; 55: 74-108.

40 World Health Organization. Cancer. Fact sheet No. 297, February 2006. www.who.int/mediacentre/factsheets/ fs297/en/. Date last accessed: October 9, 2007.

41 World Health Organization. WHO Framework Convention on Tobacco Control 2005. Geneva, Switzerland, WHO Press, 2005. www.who.int/tobacco/framework/WHO_FCTC_ english.pdf. Date last updated: 2005. Date last accessed: October 9, 2007. 